\title{
A Study of Traumatic Experiences of Female Characters in Sophia Khan's Novel
}

\author{
"Yasmeen" \\ * Mehreen Zafar, Lecturer \\ ** Dr. Muhammad Ahsan, Lecturer (Corresponding Author) \\ *** Dr. Zahoor Hussain, Lecturer
}

\begin{abstract}
The current study aims to explore the traumatic experiences of female characters of Sophia Khan's Yasmeen. M. Balaev (2014) identified "the concept of trauma as pathological and unspeakable" in the genre of trauma fiction. The insights Bloom's Psychological Trauma Theory (1999) provided the theoretical framework for the descriptive and critical textual analysis of the novel which in turn disclosed the traumatic experiences of leading female characters, Yasmeen, Irenie, Celeste and Mehrunissa. The current study is in the qualitative paradigm of research and suggested through findings that the female characters are suffering from various traumatic experiences resulted through the loss, distrust, immoral values, and re-enactment; the teenage young characters, Irenie and Celeste can dilute the trauma by dissociating the emotions whereas Yasmeen and Mehrunissa, the adult characters cannot cope their traumatic experiences. Though the traumatic experiences of all characters are separate in content and degree but the traumatic experiences of 'Evolution's legacy', emotions of loss, and 'Learned helpless', constrained actions, are common to all female characters.
\end{abstract}

Keywords: Trauma, Evolution's legacy, Dissociation, Yasmeen, Trauma Fiction Introduction

"I know my mother is dead the day I find the box" (p.3)

Fiction is the representation of society and through its characterization, the readers get close to set one's own mental and emotional catharsis. To relate self with others, novel as fiction is the best source as the setting, plot, events and characterization with personal and cultural boundaries describe the story and readers place identity and psyche of characters in a larger cultural context and explore the personal, social and psychological experiences. Psychological experiences, further, are identified as emotional and mental disturbances or trauma; it is the emotional response for the disrupting event that, moreover, creates an uncomfortable situation for the individual. Balaev (2014) identified "the concept of trauma as pathological and unspeakable". The current study focuses to explore the psyche of characters of the novel because of its very much incorporation in society. Woolf (1929) mentions women writers' interest in novels. Yasmeen, the novel is about mainly the story of a daughter who discovered the hidden love affair of her mother during her presumed death. Sophia Khan, the author of the novel Yasmeen, has done an effort job by adding passages of love letters as chapter headings epigraphically; the theme of trauma in the novel got a doubled impact. The coherent narratives to put the images of certainty of absence and the uncertainty of loss developed the environment of psychoanalysis of the characters. The unusual female and male characters, setting of the story in two different parts, switching from the state of trauma to hope, and the narratives in Pakistani context incited the urge to explore the traumatic aspects of characters. Three major male characters and four leading female characters threw strange personality traits and personal and social reactions in the emotional arena. The strong feminist discourse helped to stand out the female characters at the front. Therefore, the current study, to explore the psychological traumatic experiences of female characters in Yasmeen, was carried out. The distinction of the study highlights the importance of the current research in terms of the theoretical framework, fiction, and nature of the study.

\footnotetext{
* Department of English, Ghazi University Dera Ghazi Khan, Pakistan. Email: mzafar@gudgk.edu.pk

** Department of English, Ghazi University Dera Ghazi Khan, Pakistan. Email: mahsan@gudgk.edu.pk

*** Department of English, Bahaudin Zakariya University, Layyah Campus, Pakistan.

Email: zahoor_linguist@bzu.edu.pk
} 


\section{Distinction of the Study}

Much work has been done in American, British, and other foreign literature in the current perspective. But Pakistani fiction is still to be explored in traumatology. The study explores the unusual trauma of females; traumatic experiences of daughters due to the hidden affairs of their mothers reflect the complexities of women's character. Therefore, the current study stands prominent. The main reason for its uniqueness is that it has been carried out in the Pakistani context along with the untraditional theoretical framework of Bloom (1999) which was applied in "Trauma and the female body: An exploration of representations of women in contemporary women's writing" by Rebecca Claire March (2017).

\section{Objectives of the Study}

The main objectives of the study were as follows:

i. $\quad$ To conduct a psychological traumatic analysis of females.

ii. To analyze the repressed psychological tensions.

iii. To assess the feelings, emotions, and mentality of females.

\section{Statement of the Problem}

The study aims to explore the traumatic experiences of female characters in the novel "Yasmeen" written by Sophia Khan by deconstructing the incidents, characters, settings, emotions, and ideology of characters.

\section{Research Questions}

The current study has the following research questions:

i. Are the female characters of the novel embodiments of the psychological traumatic experiences?

ii. How do female characters deal with their psychological traumas?

iii. How do the traumatic narratives reflect the causes of the psychological traumatic experiences?

\section{Limitation and Delimitation}

Though the whole novel is in the genre of trauma fiction. All characters represent mental distractions but the current study is limited to the traumatic experiences of female characters of the novel and the traumatic experiences of male characters are ignored.

\section{Review of Literature}

Trauma, the word, deriving from Greek is to represent the complexities of physical and mental disturbances. It represents the external and internal wounds that, further, are sustained by the psyche. Everyone can see the external wounds but internal wounds are unseen unless these burst out in the form of traumatic reactions. Literature represents the social, psychological, economic, and religious aspects of people through its narratives. Therefore, the knowledge of traumatology can be understood with the reference of literary texts. Whitehead (2004) argues that the effects of trauma can be adequately incorporated in literary form by identifying the psychological collapse of events and characters. Whitehead coined "Trauma Fiction" as a genre that introduces trauma as psychological trauma in literature. According to Caruth (1996), trauma remains alive inside the individual to strike one's psyche even years after the real incident. The trauma studies in literature got acclaimed with the publication of Caruth's (1996)'s 'Unclaimed Experience: Trauma, Narrative, and History' and Kali Tal's (1996)'s 'Worlds of Hurt: Reading the Literatures of Trauma'. Both followed the principles of Freud and Lacan. Freud (1916) emphasized the psychoanalysis in terms of making the 'unconscious as conscious' by introducing Id, ego, and superego. Following him, the Lacanian approach (1979) for the human psyche being framed within the three orders of 'The Real, The Symbolic and The imaginary' (RSI) conceptualizes trauma "as a recurring sense of absence that sunders knowledge of the extreme experience". Parker (2008) mentions that the recent trauma theory is used to "assert the position that traumatic experience produces a temporal gap and dissolution of the self." There are huge examples and implications of the trauma theory and approaches in the literature. The literary works of Dorothy Allison, Tony Morison, Edward Abbey, Margaret Atwood, Alice Walker, and Eimear McBride are the few reflections of psychological trauma theory in fiction. Literary critics such as Leys (2011) and Cvetkovich (1992) create the recent psychological frameworks for trauma's impact upon language, ideology, and society. Mondragon (2016) commented that the development of trauma theory in literature can be understood by accepting changing psychological definitions of 
trauma in semiotic, rhetorical, and social perspectives which are the part of trauma study in literary and cultural context.

Concerning the related literature in the field of trauma study in literature, the current study adopts the theoretical framework of Bloom, (1999) as it covers not only traumatic experiences but also suggests some remedies for the traumatic experiences.

\section{Research Methodology and Theoretical Framework}

This research is a qualitative model of study and descriptive to explore the traumatic experiences of female characters of the novel Yasmeen. The deconstruction of the characters would be done by the textual analysis of the novel under the theoretical framework of Bloom's Psychological Trauma Theory (1999). Terr (1990) cited in Bloom (1999) quotes, "psychic trauma occurs when a sudden, unexpected, overwhelming intense emotional blow or a series of blows assaults the person from outside. Traumatic events are external, but they quickly become incorporated into the mind" (p.8). The traumatic experience can impact the whole life of the sufferer. The psychological trauma theory coins certain aspects that help to understand the traumatic experiences of the person. Evolutions' legacy indicates the importance of the amount of emotions; humans are born with emotions. One can be successful by controlling emotions. The excess of emotions can damage the person's ideology and life. The learned helplessness aspect of the theory guides us to understand how a person can be in trauma after finding oneself helpless. When the situation is not in the control of the person; the person may suffer from trauma. Loss of volume control deals with the adjustment of the emotions. It is the reaction to the stress that people adopt to cope with the emotion of fear. Thinking under stress-action not thought directs that people under stress jump towards the hurried and mistaken action. As they are thinking under stress that leads towards the wrong behavior without being judgmental. Jenis (1982) comments, "the decisions in the result of stress are inflexible, oversimplified, directed towards action, and poorly constructed". Remembering under stress leads towards the recalling of non-verbal images or the language. In extreme stress, the mind loses control over words, and at that time the visuals, audio, olfactory, and other non-verbal flashbacks work in the mind and are reflected in the personal action. In Emotion and trauma-Dissociation, dissociation is defined as "a disruption in the usually integrated functions of consciousness, memory, identity, or perception of the environment" (Bloom, 1999). It is human capacity that to stop the high traumatic state, people focus on something else; they negate the stress for some time as people escape in literature.

Traumatic re-enactment is defined by Freud in Kolk and Ducey (1989) as, "The person reproduces it not as a memory but as an action; he repeats it, without, of course, knowing that he is repeating... He cannot escape from this compulsion to repeat, and in the end we understand that this is his way of remembering" (p.271). Trauma and the body covers the idea that "victims of chronic trauma, abuse and neglect often suffer from a multitude of physical disorders not directly related to whatever injuries they have suffered" (Bloom, 1999). The psychological disturbance results in physical damage.

The critical textual analysis was carried out by applying the mentioned aspects of psychological trauma theory.

\section{Data Analysis}

The type of analysis employed is 'critical textual analysis' highlighting the traumatic experiences of female characters. The critical textual analysis of the novel answered the research questions by relating incidents with traumatic narratives and theoretical aspects. The setting and plot of the story provided the contextual information in which traumatic narratives were woven.

The story opens up with the first-person narrative, in the voice of Irenie, Yasmeen's teenage daughter. Irenie is uncomfortable with the disappearance of her mother about her father does not tell her anything. It is assumed that her mother, Yasmeen, is dead. In the absence of her mother, Irenie cooks, keeps the house perfumed, tidies her father's office, and misses her mother. Her father, James, is a very gentle and mannered person who hides his emotions for Irenie and Yasmeen in front of Irenie and keeps himself very much composed. He teaches Classical Literature at Crawford College. James lives with the emotional burden of his sister Irene's premature death by drowning during their childhood. Irenie and James are physically close but emotionally they are apart and do not communicate their sorrow of Yasmeen's disappearance with each other. The story is in two parts; in the first part, the story revolves around Irenie, missing Yasmeen, James, Celeste, and her mother Selene in College town in USA, and in the second part, Irenie visits Pakistan where she gets familiar 
with Mehrunissa, Ahmad and their son Firdaus and explores the answers of her own identity and her mother's disappearance. Irene discovers her mother's secret love affair and finds hundreds of letters from her mother and her lover Ahmad. This creates a mental distraction in her and she moves to Pakistan to solve the mystery of her mother's relationship with Ahmad and her fatherhood. Irenie's stay in Pakistan without her father James answered her all questions and beaks out the passive relation of daughter and father on her return to the US.

The story is unusual and does not represent the story of every day. The major characters are Yasmeen, James, Ahmad, Irenie, Celeste, Mehrunissa, and Firdaus. The protagonist Yasmeen is omnipresent; she is an unseen character and remains known indirectly. Irene, the daughter of Yasmeen and James, discovers the love-letters which reveals the intimate relation of her mother and her lover Ahmad. She shares her feelings and letters with her friend Celeste whose mother is also mad. "I announced the instant we found ourselves alone" (p.38). The two little teenage girls suffered the mental distractions because of their mothers. Firdaus, the son of Ahmad and Mehrunissa, who solves the secret of Yasmeen's death with his father. The critical textual analysis with the reference of traumatic narratives of major female characters fulfills the statement of the problem.

The novel is named on the character Yasmeen who is missing but is represented through the character of daughter. The reader finds her beautiful, charming, intelligent, and emotional. She is in love with Ahmad and both families are not reluctant with their relationship but just because of her overwhelmed egoistic behavior, she lost her love. "Too passionate. Too dramatic. Not to mention, much too stubborn" (p.206). She was very much in love with Ahmad even after her marriage with James, she disclosed her past love affair to her husband and acclaimed to have that love in the future as well. "And I will always be" (p.236). It represents the strength of her emotions. Yasmeen was found helpless after discovering Ahmad's disease. She got the melancholic fits, found in the drunk condition, and stopped crying just to say, "Ahmed is dying" (p.132). As a reaction to the traumatic experience of Ahmed's disease, Yasmeen tried to do suicide (p.138). The incident was described in Irenie's words, "after I found her in the tub" (p.137).

Though the novel is named Yasmeen but the strongest female character of the novel is Irenie who was just 10 years old when her mother disappeared and she suffered the trauma of losing her mother. Initially, missing mother was a question for her "For the first time I realized it has always been a question" (p.168). The major traumatic experience of Irenie was the discovery of her mother's love affair. This discovery further questions her mother's loyalties "I can't imagine my mother so carefree" (p.35) and her own identity "Is he my father?" (p.207). Irenie was suffering much mental stress after knowing the intimate relationship of Ahmed and Yasmeen, her mother. She found the love letters of 'Ahmed to Yasi and Yasi to Ahmed'. One day she found a painted box which carried a wrapped parcel full of letters. As she identified the handwriting of her mother and found a signature at the bottom of the letters. "So many letters, my mind screams" (p.11). For any child especially a daughter, the image of the mother is eternal; she is the world for the child. Yasmeen was the center for Irenie (p.14) but the hidden part of Yasmeen's life brought her into the light and caused trauma for her daughter "I came close to hating my mother" (p.14). Exploring mother as the beloved of someone's is not a good experience for Irenie but she still soothes herself for her father. "I must not panic, I tell myself" (p.12). She tries to help her father in tidying his office. Getting busy making cookies with Celeste, playing at the beach, devising sand cakes, and cooking food all were the ways to control the traumatic experiences which she had. Her sense of losing her mother and then knowing her secret love affair haunted her thoughts and memories so much that she recalled and learned to adopt her mother's choices of qawwalis, poems of Faiz and Dickinson and whiffing of perfumes (p.6) and "pretend she is still here" (p.65). Irenie got many traumatic feelings as she used to recall her mother and her love letters to Ahmed "You act like she is going to come back" (p.39). It is Celeste who provides dissociation from trauma and emotion so that Irenie cannot go through serious trauma "She is giving you your independence" (p.49). Irenie was the character of the novel who suffered high traumatic experiences; she moved to Pakistan just to handle her traumatic feelings which were aroused with the disappearance of her mother and turned intense after discovering 'two thousand four hundred and fifty-six pages' as love letters of her mother.

Celeste, another female character of the novel, is the friend and next-door neighbor of Irenie. After the disappearance of Yasmeen, Irenie spent much time with Celeste. Initially, Irenie was not close to her but the same traumatic experiences brought them close to each other. Irenie lost her 
mother and her father was physically present; emotionally they are apart. The reverse situation was with Celeste. Her father was 'dead' and her mother was not well mentally (p.38). Celeste mentioned her 'mother's boyfriends' and residence in 'yurt' (p.39). Celeste was helpless to make her mother understand her brother's health and indulge in a relationship with other boys for finding a sincere one. She soothes herself by creating noise, playing at the beach, and gossiping with Irenie. She mentions. "Irenie, do you know how many Selene's boyfriends I have seen come and go?" (p.52)

Mehrunissa, the other character, kept a strong feeling for Ahmed. "To her, he seemed far worldlier than any of the silly young men" (p.257) she loved him but Ahmed had no such feelings for her (p.258). Once at a party, Ahmed and Mehrunissa both got drunk and established physical relations so they got married but she could not get the love and affection of her husband "The husband she'd so sought was seldom home" (p.262). She lost her parents and lost husband's true love. The sense of rejection and deprivation led her towards the traumatic experience "when she realized he felt he was stuck" (p.263). Her manners and behavior did not make her wanted by anyone in society; no one likes her. She caught her husband with Yasmeen physically and it made her apathetic "This is what you threw away, she'd screamed" (p.268).

The analysis of the text with traumatic narratives leads towards the findings and the discussion of them answers the research questions in detail.

\section{Findings and Discussion}

The critical textual analysis of the text explored the psychological traumatic experiences of female characters and provided the insights to keep the novel in the genre of trauma fiction. The findings of the study are summed up in the given table to identify the major female characters with particular psychological traumatic experiences.

Table 1: Aligning characters with psychological traumatic experiences

\begin{tabular}{ll}
\hline Major Female characters & Psychological traumatic Aspects \\
\hline Yasmeen & Evolutions' legacy \\
& Learned helplessness \\
Irenie & Trauma and the body \\
& Evolutions' legacy \\
& Learned helplessness \\
& Loss of volume control \\
& Thinking under stress- action not thought \\
& Remembering under stress \\
& Emotion and trauma-Dissociation \\
& Traumatic re-enactment \\
Celeste & Trauma and the body \\
& Learned helplessness \\
& Loss of volume control \\
& Emotion and trauma-Dissociation \\
Mehrunissa & Trauma and the body \\
& Evolutions' legacy \\
& Learned helplessness \\
& Trauma and the body \\
\hline
\end{tabular}

The analysis and findings of the current study reflect that all major female characters are facing traumatic experiences. One traumatic experience, which is common to all, his sense of loss. Yasmeen lost her love Ahmed, Irenie lost her mother, Celeste lost her father, and her mother is crazy and Mehrunissa lost her husband earlier emotionally and then physically. Though all female characters are suffering their own traumatic experiences but still their emotional weakness tied them in a sisterhood.

Evolutions' legacy: Yasmeen's mad love for Ahmed, her stubbornness, her egoistic approach, Irenie's love for her parents, pinching questions of her mind to explore the mother's secret love affair and her own identity, Mehrunissa's crush on Ahmed and her Id to get him all are the representation of evolution's legacy where one cannot control emotions and get under the trauma situation. The overwhelmed emotions of Yasmeen and Mehrunissa led them towards the traumatic experiences of sorrow, melancholy, distress, and even death. Whereas Irenie's emotional quest arises trauma for her till she explores the reality and it was her trauma which provides stimulus for her to dig out the reality of love letters and missing mother. On her return to the US, she aims to get close with her father 
emotionally. The new science of trauma theory, unlike the traditional one, refers to "make the point that it is not the trauma itself that does the damage. It is how the individual's mind and body reacts in its unique way to the traumatic experience in combination with the unique response of the individual's social group" (Bloom, 1999)

Learned Helplessness: The current feature is present among all characters which reflects the overall weak and dependent personality trait of females. Morris and Spivak (2010) has defined as "the genre of the subaltern giving witness to oppression, to the less oppressed other" highlights the sound of pain from helplessness. Yasmeen's crying, leaving Ahmed, marrying James, committing suicide, Irenie's silence on the disappearance of her mother, hiding love letters of her mother, no emotional connection with father over the same grief, moving to Pakistan without father, exploring answers alone, Celeste's no control over her mother, observing mother's boyfriends and Mehrunissa's one-sided love for husband reflected the helpless traumatic aspect of female characters well.

Loss of volume control and Emotion and trauma-Dissociation: Irenie and Celeste both representing youth reflected the loss of volume control. This is important to release the traumatic element. Yasmeen and Mehrunissa were dealing with their traumas separately and all alone whereas Irenie and Celeste were sharing their ideas, beliefs, and traumas. Therefore, sharing helps them to adjust to their traumas. Through healthy activities like reappraisal, distancing, expressing suppressions, and social alignment, both teenagers dilute their traumatic experiences. Both tried to dissociate their emotions with their trauma state. Celebrating Birthdays, swimming at the beach and other fun activities are to create the gap and reduce the impact of trauma.

Thinking and Remembering under stress and Traumatic re-enactment: Only Irenie performs this traumatic experience; she recalls her mother and memories her acts in home because she wanted to feel the presence of her mother in home. Her missing mother and she are spiritually connected and Irenie pretends as her mother is around her. Psychologists in general theory confirms, "Pretend play might be a tool that helps children realize that thoughts, not reality, guide people's actions, utterances and emotions" (Beth, 2002). Irenie was so bound with her mother's thoughts that she placed the question of identity, again and again, read Yasi-Ahmed's love letters many times, and re-enacted her loss repetitively throughout the first section of the novel.

Trauma and the body: Yasmeen's emotional disturbance burst out physically and she committed suicide. Her physical relationship with Ahmed identified through their love letters made Irenie mentally disturbed. Irenie's traumatic experience with her body was limited to take bath in public in her swimming costume. Celeste fell into a physical relationship with other boys just as the reaction of finding her mother's boyfriends. Mehrunissa's illegal pregnancy became the source of her traumatic experiences. Either traumatic feelings led towards the misuse of body or body led towards the traumatic experiences but that is to ensure that all major female characters suffered traumatic experiences with their bodies. Their passive reaction through their bodies affirm their weakness and traumatic experiences.

The story of Yasmeen, in descriptive style, is told via Irenie's first-person voice in some starting chapters and then switches to the third person. The analysis and findings answered that yes, all major female characters are the embodiment of their traumatic experiences; though their experiences are varying in content and degree but they all do suffer. The traumatic narratives of the text revealed the traumatic experiences of the female characters. The traumatic narratives represent female characters as depressed, isolated, mentally disturbed, alienated, and covered under some other clocks. Traumatic narratives discloses the importance of family ties and sharing with dear ones. Comparatively, Irenie suffered much stressed as compared to the other female characters but it was her controlled power of mind that led her to move independently, explore successfully, resets the relationships emotionally, and enjoying the other mental arena. Out of four major female characters, the two Yasmeen and Mehrunissa were unable to cope with their psychological trauma but the teenage girls, through dissociation and techniques of remembering and thinking through action, tried to cope with their psychological trauma.

\section{Conclusion}

After a detailed study of psychological traumatic experiences of female characters, it can be concluded that the writer presented a unique idea in Pakistani English Literature and described the human emotions, feelings and attitudes, and psyche of relationships. Overall, the fiction falls in trauma fiction but the female characters of Sophia Khan's novel are passing through various mental 
disturbances. The writer identified the strength of emotions in the right content and time. Overwhelming or disappearance of emotions also leads to an abnormal situation. The female characters are restless and unsatisfied. The female characters are obsessed and depressed. Therefore, they are more with others as compared to their legal relationships. The reason can be of their ignorance by their real relations. Their unconscious makes them disturbed but identifying the right emotional attachment with the right person provides the eternal happiness and satisfaction as Irenie does at the end.

\section{References}

Abbey, E. (1968). Desert solitaire; a season in the wilderness. New York: McGraw-Hill

Allison, D. (1949). Bastard Out of Carolina. New York

Atwood, M. (1979). Surfacing, Virago Press: London

Balaev, M. (2014). Contemporary approaches in literary trauma theory.

Beth A. (2002). The Power of Pretending [retrieved from https://www.apa.org/monitor/mar02/ pretend. aspx on 8.10.18]

Bloom, Sandra L. (1999). Trauma Theory Abbreviated, from the Final Action Plan: A Coordinated Community-Based Response to Family Violence, Attorney General of Pennsylvania's Family Violence Task Force

Caruth, C. (1996). Unclaimed Narrative: Trauma, Narrative and History, Johns Hopkins University Press

Cvetkovich, A. (1992). Mixed feelings: Feminism, mass culture, and Victorian sensationalism. New Brunswick, N.J: Rutgers University Press.

Freud, S. (1916). Introductory lectures on psychoanalysis. SE, 22: 1-182.

Janis, I. L. (1982). Decision making under stress: Theoretical and Clinical Aspects, Free Press: New York. p. 69-87

Lacan, J. (1979). Four Fundamental Concepts of Psychoanalysis. Harmondsworth: Penguin Books.

Leys, R. (2011). The Turn to Affect: A Critique. Critical Inquiry, 37(3), 434-472. Doi: $10.1086 / 659353$

McBride, E. (2014). A Girl is a Half-formed Thing, Faber \& Faber: London

Mondragon, B. C. (2016). Neurotic Poets. [Retrieved from http://www.neuroticpoets.com/dickinson/ on 8.10.18]

Morris, R. C., \& Spivak, G. C. (2010). Can the subaltern speak? Reflections on the history of an idea.

Parker, R. D. (2008). How to interpret literature: Critical theory for literary and cultural studies.

Rebecca C. M. (2017). Trauma and the female body: An exploration of representations of women in contemporary women's writing, bright ONLINE student literary journal, vol. no.7

Tal, K. (1996). Worlds of Hurt: Reading the Literatures of Trauma. Cambridge Studies in American Literature and Culture. Cambridge, MA: Cambridge UP

Terr, L. (1990).Too Scared to Cry: Psychic Trauma in Childhood, New York: Harper and Row.

Toni M. (1970). The Bluest Eye. - New York: Holt, Rinehart \& Winston

Van der Kolk, B.A., and C.P. D. (1989). The psychological processing of traumatic experience: Rorschach patterns in PTSD. Journal of Traumatic Stress

Walker, A. (2004). The Colour Purple, Phoenix: London

Whitehead, A. (2004). Trauma Fiction, Edinburgh University Press

Woolf, V. (1929). A Room of One's Own 